\title{
Influence of pregnancy on long-term progression of retinopathy in patients with type 1 diabetes
}

\author{
C. S. Arun $\cdot$ R. Taylor
}

Received: 31 October 2007 / Accepted: 22 February 2008 /Published online: 8 April 2008

(C) Springer-Verlag 2008

\begin{abstract}
Aims/hypothesis Pregnancy in type 1 diabetic women is associated with risk of worsening of retinopathy. It has been reported that deterioration continues in the months after delivery, but direct data are lacking. It is also unclear what impact pregnancy has on the long-term progression of retinopathy.

Methods We studied 59 women with type 1 diabetes who had retinal photographs before pregnancy and yearly for 5 years post pregnancy. These photographs were graded using the EURODIAB retinopathy grading system.

Results The mean duration of diabetes was $14.4 \pm 8.2$ years and mean age at pregnancy was $29.8 \pm 5.5$ years. Mean $\mathrm{HbA}_{1 \mathrm{c}}$ was $8.2 \pm 2.0 \%$ before pregnancy with tighter control during pregnancy itself. This value was high despite efforts to improve take-up of pre-conception care. Mean $\mathrm{HbA}_{1 \mathrm{c}}$ was $8.6 \pm 1.5$ during the follow-up period. At baseline, 43 $(72.9 \%)$ women were free of retinopathy, 15 had nonproliferative retinopathy and one woman had previously had laser therapy. During pregnancy four women required laser therapy. Over the next 5 years none required laser therapy, although retinopathy worsened in 14 women. Ten-
\end{abstract}

C. S. Arun · R. Taylor

Royal Victoria Infirmary and Diabetes Centre,

Newcastle upon Tyne, UK

R. Taylor

Institute of Cellular Medicine, Newcastle University,

Newcastle upon Tyne, UK

C. S. Arun $(\bowtie)$

Department of Diabetes and Endocrinology,

Darlington Memorial Hospital, Durham and Darlington NHS Trust,

Darlington DL3 6HX, UK

e-mail: csarun2003@yahoo.co.uk year follow-up data were available on 22 women, one of whom required laser therapy 8 years after pregnancy. Baseline retinopathy status was the only independent risk factor which predicted progression of retinopathy.

Conclusions/interpretation Pregnancy is not associated with post-partum worsening of retinopathy.

Keywords Diabetic retinopathy - EURODIAB grading · Pregnancy · Type 1 diabetes

Abbreviation
NPDR non-proliferative diabetic retinopathy

\section{Introduction}

The long-term effect of pregnancy on maternal health is a serious consideration for women with type 1 diabetes who are contemplating childbirth. It is well documented that retinopathy can progress during pregnancy in type 1 diabetic women with reported rates ranging from $17 \%$ to $70 \%$ [1-3]. Poor glycaemic control, longer duration of diabetes, greater fall in blood glucose in early pregnancy and raised blood pressure have previously been identified as risk factors for progression of retinopathy during pregnancy $[4,5]$. However, data are lacking on the impact of pregnancy on retinopathy incidence and progression, and specifically on the development of sight-threatening diabetic retinopathy in the months and years after pregnancy.

Study of women who became pregnant during the Diabetes Complications and Control Trial suggested that pregnancy was associated with a continued more rapid progression of retinopathy for 12 months post-partum. No retinopathy requiring treatment was seen in this group of 
women who had relatively short duration diabetes [6]. Other studies have confirmed the increased association of sight-threatening retinopathy with pregnancy, but have not defined whether the period of risk extends beyond the pregnancy itself. The Pittsburgh Epidemiology of Complications of Diabetes Study examined the 2 year period in which a pregnancy occurred and found an approximately threefold increase in proliferative retinopathy incidence compared with non-pregnant control women [7]. While sight-threatening deterioration in retinopathy early in pregnancy is universally acknowledged, it is important to determine whether there is a need for more frequent retinal screening in the months after delivery. It is plausible that the well recognised short-term deterioration in diabetic retinopathy during pregnancy could be associated with lasting microvascular changes that could enhance rate of subsequent progression.

The present study was designed as a longitudinal observational study of retinopathy status during and over the 5 years following pregnancy with the aim of quantifying the change in grade of retinopathy and requirement for laser therapy of sight-threatening retinopathy. The study was possible as Newcastle upon Tyne has a long-established photographic retinal screening system [8-11] and a database recording diabetes care in pregnancy [12-14].

\section{Methods}

The Newcastle Diabetes Centre provides retinal screening for Newcastle District (population 270,000), UK. Two static retinal cameras are used to screen patients attending for specialist care and patients whose diabetes is managed in the community. The digital retinal screening programme in Newcastle District has annual population coverage of over $80 \%$. The screening is performed by trained retinal screeners who measure visual acuity, instill tropicamide, carry out retinal photography, assess the images and explain the findings to each individual patient. In pregnancy, retinal examination is carried out at booking and at 28 weeks for all women. If any retinopathy is present at booking, interval screening is then carried out as indicated by degree of retinopathy. Close links with the Ophthalmology Department ensure that pregnant women with sight-threatening retinopathy are assessed within 2 weeks of detection.

We identified 59 women with type 1 diabetes for whom retinal photographs were available before and at least 5 years after an index pregnancy. All pregnancies resulted in live births and had antenatal care provided in the combined obstetric and diabetic clinic at Royal Victoria Infirmary, Newcastle. All pregnancies occurred between 1989 and 1998. A pre-pregnancy service was commenced in 1990. At annual review, all women were advised about
Table 1 Clinical characteristics of 59 women with type 1 diabetes who became pregnant between 1989 and 1998

\begin{tabular}{ll}
\hline Characteristics & Values \\
\hline Age of women at delivery (years) & $29 \pm 5$ \\
Duration of diabetes at delivery (years) & $14 \pm 8$ \\
$\mathrm{HbA}_{1 \mathrm{c}}(\%)$ & \\
Before pregnancy & $8.2 \pm 2.0$ \\
At 12 weeks gestation & $7.2 \pm 1.3$ \\
At about 36 weeks gestation & $6.7 \pm 1.3$ \\
First year after pregnancy & $8.0 \pm 1.7$ \\
Average HbA $\mathrm{Ac}_{1 \mathrm{c}}(\%)$ over the next 6 years & $8.6 \pm 1.5$ \\
Blood pressure (mmHg) before pregnancy & $120 \pm 18 / 74 \pm 12$ \\
Average blood pressure (mmHg) after pregnancy & $123 \pm 15 / 73 \pm 10$ \\
\hline
\end{tabular}

Values are mean $\pm \mathrm{SD}$

the need for excellent control peri-conception, and approximately $25 \%$ of them had individualised tightening of diabetes control prior to conception [12]. The insulin regimen most suited to the individual woman was used. Following pregnancy, all women attended the Diabetes Clinic at Newcastle Diabetes Centre and had retinal photographs done at the annual review clinic. Ethical approval for the study was obtained from the Newcastle Local Research Ethics committee.

Demographic and clinical details were collated from the clinic records. The retinal photographs before booking, after delivery and yearly thereafter were obtained from the Newcastle Eye-screening Service database. All photographs were graded by a trained observer (C. S. Arun). An established grading system (EURODIAB) was used to classify the retinal changes [15]. This system has been previously validated [16] and allowed classification of retinopathy into early non-proliferative diabetic retinopathy (NPDR), moderate NPDR, severe NPDR, proliferative and laser-treated retinopathy based on the above grading

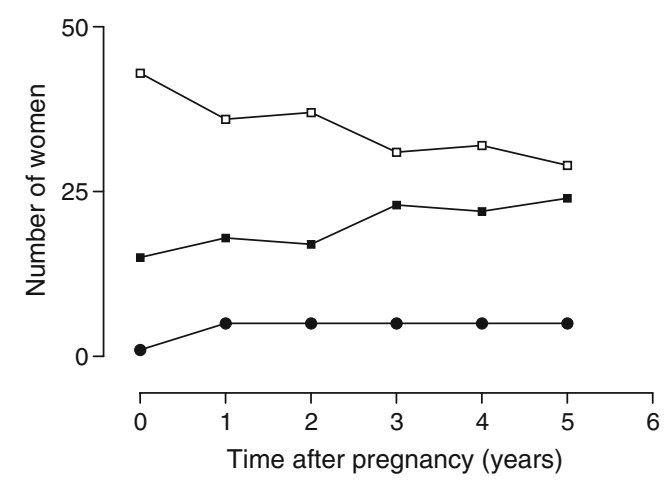

Fig. 1 The number of women in whom laser therapy was required increased from one to five during pregnancy, with no further increase after delivery (black squares). There was a steady increase in number of women with background retinopathy at any one time (circles) and a steady decrease in women with no diabetic retinopathy (white squares) 
Table 2 Details of progression or development of retinopathy during pregnancy and over 5 and 10 year periods after pregnancy

\begin{tabular}{llll}
\hline Change & During pregnancy $(n=59)$ & In next 5 years $(n=59)$ & After 10 years $(n=22)$ \\
\hline New background retinopathy & $5^{\mathrm{a}}$ & 10 & 4 \\
Progression of retinopathy & 5 & 0 & 1 \\
Significant progression requiring laser therapy & $4(8.4)$ & 0 & $1(4.5)$ \\
\hline
\end{tabular}

Values are $n(\%)$

${ }^{a}$ Changes regressed in one patient after the first year

${ }^{\mathrm{b}}$ All patients who received laser therapy had early NPDR at baseline

system. The need for laser therapy was taken as the endpoint of retinopathy progression.

The difference in deterioration in EURODIAB score on severity of retinopathy (years 2-6) was compared between the groups who exhibited no change during pregnancy and those who exhibited a deterioration of more than one grade during pregnancy. Comparison was done using the MannWhitney $U$ test.

\section{Results}

The mean age of women at the time of pregnancy was $29.8 \pm$ 5.5 years with duration of diabetes of $14.4 \pm 8.2$ years. $\mathrm{HbA}_{1 \mathrm{c}}$ was $8.2 \pm 2.0 \%$ pre-pregnancy and $8.6 \pm 1.5$ during the follow-up period. The baseline systolic and diastolic BP prior to pregnancy was $120 \pm 18$ and $74 \pm 12 \mathrm{mmHg}$ respectively (Table 1).

At baseline, 43 (72.9\%) patients were free of retinopathy and 15 had background retinopathy (14 early NPDR, 1 moderate NPDR; Fig. 1). One patient had already received laser therapy for bilateral maculopathy before pregnancy. During pregnancy four women required laser therapy, three of whom had macular oedema and one proliferative retinopathy. One other woman developed bilateral moderate NPDR during pregnancy, but did not receive laser therapy. No women with a previously normal retina went on to receive laser therapy during pregnancy. Although 10 patients progressed from normal to early NPDR within 5 years, none progressed to require laser therapy (Table 2).
In univariate analysis, the presence or absence of retinopathy at baseline was found to be the only significant risk factor for progression $\left(\chi^{2}=12.3, d f=1, p<0.001\right)$. Age, duration of diabetes, pre-pregnancy $\mathrm{HbA}_{1 \mathrm{c}}$ and systolic $\mathrm{BP}$ were not significantly different in women who received laser therapy (Table 3).

Follow-up information to 10 years was available for 22 women. One woman developed maculopathy requiring laser therapy 8 years after pregnancy, having had early background retinopathy at baseline. Within this group of 22 women, 12 had no progression, four had mild progression and three regressed from the time of delivery to the end of follow-up. All three women whose retinopathy regressed over the years after pregnancy had only a few microaneurysms during pregnancy, which disappeared within 1 year. For two women who had received laser therapy during pregnancy data at 10 year follow-up were available. They had no further worsening over this period.

\section{Discussion}

No deterioration in retinopathy was observed in the first year after pregnancy, and in particular there was no requirement for laser therapy over this time. Pregnancy appeared to have no deleterious influence on the subsequent development of sight-threatening retinopathy. Progression of retinopathy requiring laser during pregnancy was noted in four of $59(6.8 \%)$ patients, whereas only one of 22 women progressed to receive laser therapy over the next 10 years.

Table 3 Baseline characteristics of those who did or did not show progression of retinopathy during pregnancy

\begin{tabular}{lllc}
\hline & Progressors $(n=4)$ & Non-progressors $(n=54)$ & $p$ value \\
\hline Retinopathy at baseline, $n(\%)$ & $4(100)$ & $11(20)$ & $<0.001$ \\
Age during pregnancy (years) & $29.2 \pm 4.5$ & $29.9 \pm 5.6$ & 0.78 \\
Duration of diabetes at pregnancy (years) & $15.7 \pm 7.9$ & $14.2 \pm 8.3$ & 0.73 \\
Baseline HbA 1 (\%) & $9.3 \pm 1.2$ & $8.1 \pm 2.1$ & 0.14 \\
Systolic BP (mmHg) & $108 \pm 17$ & $121 \pm 18$ & 0.23 \\
\hline
\end{tabular}

Unless otherwise stated, values are mean \pm SD. One patient who had laser therapy before pregnancy was excluded. All women classified as progressors had early NPDR at baseline 
Diabetic retinopathy may be adversely affected during pregnancy by major changes in distribution of blood flow, an increase in cardiac output as well as hormonal changes including increased IGF-1 levels [17, 18]. In addition, sudden improvement in glycaemic control induces a decrease in retinal blood flow, secondary hypoxia and thus worsening of retinopathy $[19,20]$.

Although progression of retinopathy during pregnancy in women with type 1 diabetes has been well described, progression after pregnancy is less certain. Data from the DCCT cohort suggested that deterioration of retinopathy may continue for some months after pregnancy, even though the mean diabetes duration in the women studied was only 5 years [6]. The present study observed no progression of retinopathy requiring intervention at any time after the pregnancy in a population of women with considerable greater duration of diabetes. It is unlikely that cases were missed, as the Newcastle screening method has high sensitivity ( $88 \%$ ) and specificity $(98 \%)$, as previously described [21], and because missed cases would be picked up in subsequent years within this single centre study.

The low incidence of requirement for laser therapy over the years following pregnancy is striking. No laser therapy was required in the 59 women followed for 5 years, while only one of the 22 women followed for 10 years needed this treatment. The lack of any evident adverse long-term effect of pregnancy on retinopathy when proper surveillance is carried out in pregnancy is consistent with several cross-sectional studies. In the Pittsburgh EDC pregnancy study, the prevalence of retinopathy in 80 women who had previous pregnancy was the same as in matched nulliparous women [7]. A cross-sectional study on 28 women 7 years after pregnancy suggested a decreased rate of progression in the long term, with progression occurring in $19 \%$ of women who had been pregnant compared with $50 \%$ in nulliparous control women [22]. The end-of-study assessment in the DCCT showed no long-term effects of pregnancy on retinopathy progression in this group of women with short-duration diabetes [23]. This confirmed the Wisconsin study, which had observed no relation of gravidity to development of retinopathy [24].

It could be postulated that the slow progression noted in the present study over a longer term could be due to removal of susceptible patients from the population during pregnancy. Those women who are otherwise at risk of gradual progression of their retinopathy over a few years might have had rapid progression during pregnancy and required laser therapy. It is also possible that a period of good glycaemic control during pregnancy had a durable beneficial effect, a phenomenon shown in the EDIC study [23].

The group of women described in the present study had routine modern diabetes care, including retinal screening before, during and after pregnancy in a single clinic. It should be noted that there was a rapid improvement in control during the pregnancy itself, and ideally this would be achieved prior to pregnancy with higher take up of pre-pregnancy care. Although there is significant risk of retinopathy worsening during pregnancy, this does not continue after pregnancy. If retinopathy is stable after delivery, then progression over years is not hastened by the pregnancy.

Acknowledgements We are grateful to the retinal screeners of Newcastle Diabetes Centre, who carried out all the photography upon which this assessment was based and also to S. Aldington of the Retinal Grading Centre, Hammersmith Hospital, London, for help with application of the EURODIAB grading system. C. S. Arun was supported by a research fellowship from Eli Lilly.

Duality of interest The authors declare that there is no duality of interest associated with this manuscript.

\section{References}

1. Dibble CM, Kochenour NK, Worley RJ, Tyler FH, Swartz M (1982) Effect of pregnancy on diabetic retinopathy. Obstet Gynecol 59:699-704

2. Klein BE, Moss SE, Klein R (1990) Effect of pregnancy on progression of diabetic retinopathy. Diabetes Care 13:34-40

3. Price JH, Hadden DR, Archer DB, Harley JM (1984) Diabetic retinopathy in pregnancy. Br J Obstet Gynaecol 91:11-17

4. Axer-Siegel R, Hod M, Fink-Cohen S, Kramer M, Weinberger D, Schindel B, Yassur Y (1996) Diabetic retinopathy during pregnancy. Ophthalmology 103:1815-1819

5. Chew EY, Mills JL, Metzger BE et al (1995) Metabolic control and progression of retinopathy. The Diabetes in Early Pregnancy Study. National Institute of Child Health and Human Development Diabetes in Early Pregnancy Study. Diabetes Care 18:631-637

6. DCCT (2000) Effect of pregnancy on microvascular complications in the diabetes control and complications trial. Diabetes Care 23:1084-1091

7. Hemachandra A, Ellis D, Lloyd CE, Orchard TJ (1995) The influence of pregnancy on IDDM complications. Diabetes Care 18:950-954

8. Pandit RJ, Taylor R (2002) Quality assurance in screening for sight-threatening diabetic retinopathy. Diabet Med 19:285-291

9. Taylor R, Broadbent DM, Greenwood R, Hepburn D, Owens DR, Simpson H (1998) Mobile retinal screening in Britain. Diabet Med 15:344-347

10. Taylor R, Lovelock L, Tunbridge WM et al (1990) Comparison of non-mydriatic retinal photography with ophthalmoscopy in 2159 patients: mobile retinal camera study. BMJ 301:1243-1247

11. Taylor R (1996) Practical community screening for diabetic retinopathy using the mobile retinal camera: report of a 12 centre study. British Diabetic Association Mobile Retinal Screening Group. Diabet Med 13:946-952

12. Carron Brown S, Kyne-Grzebalski D, Mwangi B, Taylor R (1999) Effect of management policy upon 120 Type 1 diabetic pregnancies: policy decisions in practice. Diabet Med 16:573-578

13. Njenga E, Lind T, Taylor R (1992) Five year audit of peripartum blood glucose control in type 1 diabetic patients. Diabet Med 9:567-570

14. Taylor R, Lee C, Kyne-Grzebalski D, Marshall SM, Davison JM (2002) Clinical outcomes of pregnancy in women with type 1 diabetes(1). Obstet Gynecol 99:537-541 
15. Aldington SJ, Kohner EM, Meuer S, Klein R, Sjolie AK (1995) Methodology for retinal photography and assessment of diabetic retinopathy: the EURODIAB IDDM complications study. Diabetologia 38:437-444

16. Arun CS, Pandit R, Taylor R (2004) Long-term progression of retinopathy after initiation of insulin therapy in Type 2 diabetes: an observational study. Diabetologia 47:1380-1384

17. Chen HC, Newsom RS, Patel V, Cassar J, Mather H, Kohner EM (1994) Retinal blood flow changes during pregnancy in women with diabetes. Invest Ophthalmol Vis Sci 35:3199-3208

18. Tooke JE (1995) Microvascular function in human diabetes. A physiological perspective. Diabetes 44:721-726

19. Phelps RL, Sakol P, Metzger BE, Jampol LM, Freinkel N (1986) Changes in diabetic retinopathy during pregnancy. Correlations with regulation of hyperglycemia. Arch Ophthalmol 104:18061810
20. Lauritzen T, Frost-Larsen K, Larsen HW, Deckert T (1983) Effect of 1 year of near-normal blood glucose levels on retinopathy in insulin-dependent diabetics. Lancet 1:200-204

21. Arun CS, Young D, Batey D et al (2006) Establishing ongoing quality assurance in a retinal screening programme. Diabet Med 23:629-634

22. Kaaja R, Sjoberg L, Hellsted T, Immonen I, Sane T, Teramo K (1996) Long-term effects of pregnancy on diabetic complications. Diabet Med 13:165-169

23. White NH, Cleary PA, Dahms W, Goldstein D, Malone J, Tamborlane WV (2001) Beneficial effects of intensive therapy of diabetes during adolescence: outcomes after the conclusion of the Diabetes Control and Complications Trial (DCCT). J Pediatr 139:804-812

24. Klein BE, Klein R (1984) Gravidity and diabetic retinopathy. Am J Epidemiol 119:564-569 